ORIGINAL ARTICLE

\title{
Risk factors for respiratory morbidity in infancy after very premature birth
}

\author{
A Greenough, E Limb, L Marston, N Marlow, S Calvert, J Peacock
}

Arch Dis Child Fetal Neonatal Ed 2005;90:F320-F323. doi: 10.1136/adc.2004.062018

See end of article for
authors' affiliations
$\ldots \ldots \ldots \ldots \ldots \ldots . . . . .$.
Correspondence to:
Professor Greenough,
Department of Child'
Health, 4th Floor Golden
Jubilee Wing, King's
College Hospital, Bessemer
Road, London SE5 9RS,
UK; anne.greenough@kcl.
ac.uk
Accepted
16 February 2005
Published Online First
5 May 2005
........................

See end of article for authors' affiliations

Correspondence to: Professor Greenough, Health, 4th Floor Golden Jubilee Wing, King's College Hospital, Bessemer Road, London SE5 9RS, UK; anne.greenough@kcl. Accepted 16 February 2005 5 May 2005

\begin{abstract}
Objectives: To determine the occurrence of respiratory morbidity during infancy after very premature birth and to identify risk factors.

Design: Prospective follow up study.

Setting: The United Kingdom oscillation study.

Patients: 492 infants, all born before 29 weeks gestation.

Interventions: Structured questionnaires were completed by local paediatricians when the infants were seen in outpatients at 6 and 12 months of age corrected for prematurity.

Main outcome measures: Cough, wheeze, and treatment requirements and the composite measure of respiratory morbidity (cough, frequent cough, cough without infection, wheeze, frequent wheeze, wheeze without infection, and use of chest medicine) and their relation to 13 possible explanatory variables.

Results: At 6 and 12 months of corrected age, 27\% of the infants coughed and $6 \%$ had frequent (more than once a week) cough, and $20 \%$ and $3 \%$ respectively had wheeze or frequent wheeze. At 6 and 12 months, $14 \%$ of infants had taken bronchodilators and $8 \%$ inhaled steroids. After adjustment for multiple outcome testing, four factors were associated with increased respiratory morbidity: male sex, oxygen dependency at 36 weeks postmenstrual age, having older siblings aged less than 5 years, and living in rented accommodation.

Conclusions: Male infants are particularly vulnerable to respiratory morbidity in infancy after very premature birth. It is important to identify a safe and effective strategy to prevent chronic oxygen dependency.
\end{abstract}

S urvival of very prematurely born babies is increasing, but many develop chronic oxygen dependency, which in more mature preterm infants has been associated with chronic respiratory morbidity. ${ }^{1}$ Many studies, however, have reported findings from babies not routinely exposed to either antenatal steroids or postnatal surfactant, making them dissimilar to the very prematurely born infants currently cared for on neonatal units. Recent evidence suggests that very prematurely born infants may have suffered lung growth arrest in utero. ${ }^{2}$ The long term implications are unknown. It is therefore desirable to determine whether very prematurely born infants suffer respiratory morbidity in infancy and identify whether there are preventable or treatable risk factors. The United Kingdom oscillation study (UKOS) ${ }^{3}$ affords a unique opportunity to provide such data. Infants recruited into UKOS were all born before 29 weeks gestation, more than $90 \%$ received antenatal steroids and postnatal surfactant, and the study incorporated preplanned follow up including a respiratory questionnaire administered in outpatients when the infants were 6 months and 1 year of age corrected for premature birth. The aims of this study were therefore to document respiratory symptoms and treatment requirements during infancy of very prematurely born babies and to identify whether there were preventable or treatable risk factors.

\section{METHODS}

Infants were seen by their local paediatrician in outpatients at a corrected age of 6 and 12 months. At each visit, the paediatrician completed a structured questionnaire by asking the parents a series of questions about their infant's respiratory symptoms and treatment requirements and possible risk factors. The paediatrician recorded the frequency of wheeze and cough and their relation to infection. Risk factors asked about included infant, parental, and family characteristics (see below). Data from the 6 and 12 month questionnaires were only analysed if they were completed within predefined age windows of 5-8 months or 1115 months corrected for prematurity respectively. This study was approved by the South Thames Multicentre Research Ethics Committee.

\section{Statistical analysis}

Seven outcomes of clinical interest were analysed: any cough, frequent cough (more than once a week), cough without infection, any wheeze, frequent wheeze (more than once a week), wheeze without infection, and use of chest medicine (bronchodilators, inhaled or oral steroids). The prevalence of each of the seven symptoms or treatments were determined at 6 and 12 months separately, and from this a new variable was derived which denoted a positive report at both time periods as an indicator of persistent morbidity. These seven persistent symptoms and treatments were analysed with respect to 13 explanatory variables: gestational age (calculated in days), birth weight, sex, singleton/multiple birth, mode of ventilation (high frequency oscillatory ventilation or conventional ventilation), oxygen dependency at 36 weeks postmenstrual age, oxygen dependent at discharge, family history of atopy (parent or sibling had asthma, hay fever, or eczema), older siblings less than 5 years of age, breast/bottle fed, owned/rented accommodation, ownership of long haired pet (cats/dogs/rabbits), maternal smoking. Unifactorial relations were explored using $\chi^{2}$ or $t$ tests as appropriate. For each of the seven outcomes, several possible explanatory variables showed significant associations, and so multiple logistic regression was used to disentangle the relations. We initially included all the explanatory variables that were significant at the 0.10 level in the regression model. 
Table 1 Baseline data by return of 12 month respiratory questionnaire

\begin{tabular}{|c|c|c|c|c|}
\hline & $\begin{array}{l}\text { Data obtained } \\
11-15 \text { months }\end{array}$ & $\begin{array}{l}\text { Data obtained } \\
\text { outside } \\
11-15 \text { months }\end{array}$ & No data & $p$ Value \\
\hline Number & 431 & 59 & 97 & \\
\hline Birth weight $(\mathrm{g})$ & $909(205)$ & $847(223)$ & $894(190)$ & 0.09 \\
\hline Gestational age (weeks) & $26.8(1.4)$ & $26.5(1.4)$ & $26.7(1.2)$ & 0.23 \\
\hline Birth weight SDS & $-0.49(0.97)$ & $-0.73(0.94)$ & $-0.46(1.00)$ & 0.17 \\
\hline Male & $221(51 \%)$ & $33(56 \%)$ & $51(53 \%)$ & 0.79 \\
\hline Multiple birth & $96(22 \%)$ & $12(20 \%)$ & $23(24 \%)$ & 0.94 \\
\hline HFOV & $218(51 \%)$ & $33(56 \%)$ & $47(48 \%)$ & 0.66 \\
\hline $\begin{array}{l}\text { Oxygen dependence } \\
\text { at } 36 \text { weeks PMA }\end{array}$ & $247(57 \%)$ & $35(59 \%)$ & $45(46 \%)$ & 0.12 \\
\hline $\begin{array}{l}\text { Oxygen dependence } \\
\text { at discharge }\end{array}$ & $87(20 \%)$ & $19(32 \%)$ & $16(16 \%)$ & 0.06 \\
\hline
\end{tabular}

Backwards stepwise elimination was then used to remove explanatory variables that were no longer significant at the 0.05 level when analysed together in the model. The results are presented as unadjusted and adjusted odds ratios with 95\% confidence intervals. To allow for the possibility of type one errors due to testing seven outcomes, a modified $\mathrm{p}$ value was calculated for each odds ratio from the logistic regression. The Armitage-Parmar procedure, which takes account of the intercorrelation between outcomes, was used to preserve the original significance level $(0.05)$ and reduce the chance of type two error. ${ }^{4}$ It should be noted that the use of a multiple testing approach means that the individual hypotheses are no longer tested, but instead a composite hypothesis, respiratory morbidity (cough, frequent cough, cough without infection, wheeze, frequent wheeze, wheeze without infection and use of chest medicine), is tested. A variable that is associated with any of the outcomes after modification of the $\mathrm{p}$ value is thus significantly associated with the composite outcome. ${ }^{5}$

\section{RESULTS}

A total of 587 infants survived until 1 year corrected age. Questionnaires were not completed for 97 infants, and 59 were completed outside the predefined window. There were no significant differences in baseline characteristics of infants for whom respiratory questionnaire data were available within the 11-15 month window, outside the window, or not available (table 1). There were no significant differences in possible risk factors for respiratory morbidity between the same three groups (table 1). Similarly, no significant differences were found with regard to the 6 month questionnaire (data not shown). Of those with data within the age window $11-15$ months, 59\% had a family history of atopy, 34\% had older siblings less than 5 years of age, $95 \%$ had received breast milk, 34\% lived in rented accommodation, $26 \%$ of their parents were pet owners, $37 \%$ of their mothers smoked, and $13 \%$ of the infants attended nursery.

At least $40 \%$ of the infants had wheezed or coughed when seen at either 6 or 12 months, and at least $20 \%$ had wheezed or coughed when seen at both 6 and 12 months (table 2). More than $20 \%$ of the infants were receiving bronchodilators at 6 or 12 months, and more than $10 \%$ were receiving inhaled steroids (table 2).

Multifactorial analysis showed that there were several factors associated with most respiratory outcomes at both 6 and 12 months. The average correlation between all pairs of the seven outcomes was 0.41. This value was used to calculate modified p values, as described in the methods section. After correction for testing multiple outcomes, four variables were significantly associated with at least a twofold increased risk of respiratory morbidity: male sex, oxygen dependency at 36 weeks postmenstrual age, and having older siblings less than 5 years of age were positively associated, and multiple birth was negatively associated. Living in rented accommodation was also associated with increased respiratory morbidity, but only with borderline significance $(\mathrm{p}=$ 0.05; table 3).

Table 2 Frequency of respiratory symptoms at 6, 12, and both 6 and 12 months

\begin{tabular}{llll}
\hline & 6 months* & 12 monthst & 6 and 12 months \\
\hline Totalł & 386 & 430 & 459 \\
Cough & $49 \%(189 / 386)$ & $51 \%(219 / 430)$ & $27 \%(107 / 403)$ \\
Frequent cough & $20 \%(77 / 239)$ & $18 \%(76 / 427)$ & $6 \%(26 / 459)$ \\
Cough without infection & $23 \%(86 / 367)$ & $21 \%(89 / 415)$ & $6 \%(28 / 439)$ \\
Wheeze & $40 \%(152 / 382)$ & $42 \%(171 / 409)$ & $20 \%(84 / 415)$ \\
Frequent wheeze & $16 \%(61 / 375)$ & $13 \%(50 / 399)$ & $3 \%(14 / 456)$ \\
Wheeze without infection & $20 \%(71 / 362)$ & $18 \%(73 / 402)$ & $6 \%(26 / 445)$ \\
Bronchodilators & $22 \%(84 / 386)$ & $36 \%(156 / 430)$ & $14 \%(63 / 459)$ \\
Inhaled steroids & $13 \%(103 / 381)$ & $17 \%(71 / 430)$ & $8 \%(37 / 459)$ \\
Bronchodilators or inhaled & $27 \%(103 / 381)$ & $38 \%(165 / 429)$ & $15 \%(67 / 433)$ \\
steroids & & & \\
\hline
\end{tabular}

Data are percentage of positive responses to each question (number of positives/number responding to each question).

*6 month questionnaire completed at 5-8 months.

+12 month questionnaire completed at 11-15 months.

fTotals indicate maximum number responding. The 6 and 12 month analysis required children to have a positive response at both time points. Therefore children who reported "no" to a symptom at one time point and had no response (missing) at the other were classified as "no" overall. 
Table 3 Factors related to respiratory symptoms reported at both 6 and 12 months of age corrected for prematurity estimated in logistic regression analysis and modified $p$ values allowing for multiple testing

\begin{tabular}{|c|c|c|c|c|c|}
\hline \multirow[b]{2}{*}{ Outcome variable } & \multirow[b]{2}{*}{ Predictor variables } & \multicolumn{3}{|l|}{ Odds ratio } & \multirow{2}{*}{$\begin{array}{l}\text { Multiple testing } \\
\text { modified } \\
\text { p Value* }\end{array}$} \\
\hline & & Unadjusted & Adjusted $\dagger$ & $95 \% \mathrm{Cl}$ & \\
\hline \multirow[t]{4}{*}{ Cough } & Sex: boy & 1.80 & 1.83 & 1.11 to 3.02 & 0.053 \\
\hline & Oxygen dependent at discharge & 2.01 & 1.76 & 1.00 to 3.11 & 0.12 \\
\hline & Lives in rented accommodation $\ddagger$ & 1.96 & 1.67 & 1.02 to 2.73 & 0.14 \\
\hline & Older siblings aged $<5$ years $\$$ & 1.70 & 2.25 & 1.34 to 3.80 & 0.006 \\
\hline \multirow[t]{2}{*}{ Frequent cough, $>1$ per week } & Sex: boy & 2.39 & 2.62 & 1.07 to 6.42 & 0.10 \\
\hline & Older siblings aged $<5$ years & 3.35 & 4.52 & 1.92 to 10.64 & 0.003 \\
\hline \multirow[t]{3}{*}{ Cough without infection } & Oxygen dependent at discharge & 2.42 & 2.87 & 1.19 to 6.92 & 0.056 \\
\hline & Lives in rented accommodation & 2.96 & 2.39 & 1.03 to 5.54 & 0.12 \\
\hline & Older siblings aged $<5$ years & 3.23 & 3.69 & 1.59 to 8.55 & 0.006 \\
\hline \multirow[t]{4}{*}{ Wheeze } & Multiple birth & 0.36 & 0.37 & 0.18 to 0.77 & 0.024 \\
\hline & Oxygen dependent at 36 wks PMA & 2.43 & 2.74 & 1.55 to 4.83 & 0.003 \\
\hline & Pet ownership & 0.42 & 0.43 & 0.21 to 0.87 & 0.059 \\
\hline & Older siblings aged $<5$ years & 1.54 & 1.98 & 1.13 to 3.49 & 0.053 \\
\hline Frequent wheeze, $>1$ per week & Sex: boy & 13.98 & 13.56 & 1.76 to 104.71 & 0.036 \\
\hline \multirow{2}{*}{ Wheeze without infection } & Sex: boy & 2.46 & 2.68 & 1.11 to 6.45 & 0.082 \\
\hline & Lives in rented accommodation & 3.46 & 2.78 & 1.20 to 6.43 & 0.051 \\
\hline Chest medicine & $\begin{array}{l}\text { Randomised mode of ventilation at } \\
\text { birth: HFOV }\end{array}$ & 0.56 & 0.54 & 0.30 to 0.99 & 0.13 \\
\hline \multirow{5}{*}{$\begin{array}{l}\text { Bronchodilators, inhaled/oral } \\
\text { steroids }\end{array}$} & Sex: boy & 2.73 & 2.45 & 1.32 to 4.54 & 0.015 \\
\hline & Multiple birth & 0.48 & 0.38 & 0.17 to 0.85 & 0.053 \\
\hline & $\begin{array}{l}\text { Oxygen dependent at } 36 \text { weeks } \\
\text { PMA }\end{array}$ & 3.70 & 2.36 & 1.13 to 4.93 & 0.065 \\
\hline & Oxygen dependent at discharge & 4.18 & 2.08 & 1.04 to 4.14 & \\
\hline & At nursery ${ }^{\star \star}$ & 0.37 & 0.30 & 0.10 to 0.93 & 0.11 \\
\hline \multicolumn{6}{|c|}{$\begin{array}{l}{ }^{*} \text { Modified for multiple testing of seven outcomes using Armitage-Parmar method. }{ }^{4} \text { The } p \text { values thus represent the significance for the composite hypothesis, any } \\
\text { respiratory morbidity. Thus we interpret the findings as follows: any factor that is significant for any outcome is significantly associated with the composite } \\
\text { outcome. } \\
\text { †Adjusted adjusted for other factors in the model by logistic regression. } \\
\text { †Parent reported living in rented accommodation at both time points. } \\
\text { §Child had an older sibling aged less than } 5 \text { at either time point. } \\
\text { †Family had a cat or dog at either time point. } \\
\text { **Child attended a nursery at either time point. } \\
\text { HFOV, high frequency oscillatory ventilation; PMA, postmenstrual age. }\end{array}$} \\
\hline
\end{tabular}

\section{DISCUSSION}

We show that more than $40 \%$ of the very prematurely born infants had wheezed or coughed, and more than $20 \%$ had received bronchodilators when seen at 6 or 12 months corrected age. The numbers of very prematurely born infants who are surviving are increasing, therefore this ongoing respiratory morbidity is worrying as it will produce a growing burden on the health service. We did not include in our study a comparison group of infants born less prematurely or born at term, thus we cannot comment as to whether respiratory morbidity at follow up is more common in infants born very prematurely than in those other two groups. It is, however, of interest to note that in another study, whereas only $19 \%$ of children born at term had at least one episode of wheezing in the first two years, $41 \%$ of those born at a mean of 32 weeks gestation, but without chronic oxygen dependency, had that adverse outcome. Those ${ }^{6}$ and our data suggest that respiratory morbidity is common after premature birth.

Data from respiratory questionnaires were not available from all the survivors of the UKOS. Comparison of the baseline data provided little evidence of differences between infants who did or did not have respiratory questionnaire data, nor between infants whose respiratory questionnaire was or was not completed in the predefined window. The exception was that infants lost to follow up had a lower prevalence of oxygen dependency, and, although it was not statistically significant, it is possible that our estimates of morbidity are slightly inflated.

In total, we examined seven outcomes of interest and 13 potential explanatory variables, but only five variables- that is, male sex, multiple birth, prolonged oxygen dependency, living in rented accommodation (which we used as a proxy for poor socioeconomic status), and having older siblings less than 5 years of age-were significant risk factors, and four were risk factors for at least one outcome. The association of respiratory morbidity with prolonged oxygen dependency in both relatively "mature" prematurely born infants ${ }^{167}$ and the present population of very immature infants emphasises the importance of identifying a treatment that will both effectively and safely prevent chronic lung disease. Infants with older siblings less than 5 years of age are more likely to be exposed to respiratory tract infections, and this may explain why this was a significant risk factor for cough and wheeze. It has been postulated, however, that the microbial burden in the first years of life may be crucial for the development of a non-atopic response. ${ }^{8}$ It would therefore be interesting to determine whether very prematurely born infants who had had siblings less than 5 years of age were less symptomatic in later childhood.

Male sex was significantly associated with frequent wheeze and use of chest medicine. These results may reflect the fact that, at each gestational age, boys are more likely to develop respiratory distress syndrome and more severely than girls. Lung function has been found to be poorer in male than female infants born at term ${ }^{9-11}$ and in infants born on average seven weeks prematurely studied before neonatal discharge. ${ }^{12}$ It then seems likely, although not yet investigated, that similar differences might occur in very prematurely born infants and that a reduction in airway function may explain the higher occurrence of respiratory symptoms in the male infants.

Risk factors for respiratory morbidity have not been previously investigated in such a large data set of very prematurely born infants. A family history of atopy has been associated with airway hyper-responsiveness in term born infants. ${ }^{13}$ In this study, a high proportion of infants had a 


\section{What is already known on this topic}

Respiratory morbidity at follow up is increased after premature birth.

\section{What this study adds}

This study reports prospective follow up of a large cohort of very prematurely born infants. Risk factors were identified for increased respiratory morbidity (frequent cough and/or wheeze and/or treatment requirement). The risk factors were male sex, prolonged oxygen dependency, older siblings less than 5 years of age, and living in rented accommodation, emphasising the vulnerability of male infants and the importance of finding a safe and effective preventive strategy for chronic lung disease.

family history of atopy, which perhaps supports the hypothesis that a family history of maternal asthma may predispose to premature delivery, ${ }^{14}$ but we saw no significant association with a family history of atopy and respiratory symptoms or use of medication. Gestational age was not significantly associated with respiratory morbidity at follow up; but only a narrow range of gestational ages were examined. Maternal smoking was not found to be a significant risk factor, in contrast with previous findings in term born infants. ${ }^{13}{ }^{15-17}$ Urinary cotinine concentrations were not measured in our study population, but $23 \%$ of the mothers did admit to smoking, which is higher than the $16 \%$ incidence reported in the 2950 participants of the Children's Health Study, ${ }^{18}$ but similar to the $24 \%$ incidence in another large study. ${ }^{19}$ It is possible that the effect of maternal smoking is less in infants born very prematurely than at term because the cumulative passive exposure is much reduced. In children born at term, rates of lower respiratory tract illness were noted to be greater the more cigarettes per day the mother had smoked during pregnancy. ${ }^{20}$ Another potential biasing factor is that the long term effects of in utero smoking exposure may be genetically determined..$^{18}$

We analysed seven clinically relevant markers of respiratory morbidity. To avoid type one errors due to multiple testing, we adjusted our $\mathrm{p}$ values using a correction that took into account the fact that the seven outcomes were intercorrelated. ${ }^{4}$ There is debate about the appropriateness of such adjustments, with some arguing that adjustment is not warranted when multiple tests are preplanned and that using adjustments in such cases leads to loss of statistical power and the possibility that real effects may be missed. ${ }^{21}{ }^{22}$ In addition, it is argued that correction for multiple testing necessarily leads to the testing of a composite hypothesis, where the composite comprises all of the outcomes combined and that this may not be helpful in interpreting the findings in a clinical setting. ${ }^{4}$ We hold some sympathy with these views and therefore have presented the results of our finding from the logistic regression analyses using the conventional $\mathrm{p}$ values, and also the modified $\mathrm{p}$ values.

In conclusion, we have shown that respiratory morbidity is common during infancy after very premature birth. These data highlight two facts: (a) it is important to identify an effective and safe strategy to prevent chronic lung disease; $(b)$ male infants are particularly vulnerable to respiratory morbidity at follow up.

\section{ACKNOWLEDGEMENTS}

UKOS was funded by the Medical Research Council, who supported EL and LM. We thank Mrs D Gibbons for secretarial assistance.

\section{Authors' affiliations}

A Greenough, Department of Child Health, Guy's, King's and St Thomas' School of Medicine, London, UK

E Limb, L Marston, J Peacock, Community Health Sciences, St George's Hospital Medical School, London, UK

N Marlow, University Hospital, Nottingham, UK

S Calvert, Department of Child Health, St George's Hospital, London, UK Competing interests: none declared

This study was approved by the South Thames Multicentre Research Ethics Committee.

\section{REFERENCES}

1 Giffin F, Greenough A. Does the duration of oxygen dependency after birth influence subsequent respiratory morbidity. Eur J Pediatr 1994; 153:34-7.

2 Coalson JJ, Winter V, de Lemos RR. Decreased alveolarisation in baboon survivors with bronchopulmonary dysplasia. Am J Respir Crit Care Med 1995; 152:640-6.

3 Johnson AH, Peacock JL, Greenough A, et al. High frequency oscillatory ventilation for the prevention of chronic lung disease of prematurity. N Engl J Med 2002;347:633-42.

4 Sankoh AJ, Huque MF, Dubey SD. Some comments on frequently used multiple endpoint adjustment methods in clinical trials. Stat Med 1997; 16:2529-42.

5 Bland M, Altman D. Multiple significance tests: the Bonferroni method. BMJ 1995;310:170.

6 Perez Perez G, Navarro Merino M, Romero Perez MM, et al. Respiratory morbidity after hospital discharge in premature infants born at $\leqslant 32$ weeks gestation with bronchopulmonary dysplasia. An Pediatr (Barc) 2004;60: 117-24

7 Chien YH, Tsao PN, Chou HC, et al. Rehospitalisation of extremely low birthweight infants in first 2 years of life. Early Hum Dev 2002;66:33-40.

8 Riedler J, Braun-Fahrlander C, Eder W, et al. Exposure to farming in early life and development of asthma and allergy: a cross-sectional survey. Lancet 2001;358:1129-33

9 Hanrahan JP, Tager IB, Castile RG, et al. Pulmonary function measures in healthy infants: variability and size correction. Am Rev Respir Dis 1990;141:1127-35.

10 Jones M, Caastile R, Davis S, et al. Forced expiratory flows and volumes in infants. Am J Respir Crit Care Med 2000;161:353-9.

11 Lum S, Hoo A-F, Dezateux C, et al. The association between birthweight, sex and airway function in infants of non-smoking mothers. Am J Respir Crit Care Med 2001; 164:2078-84.

12 Ho A-F, Henschen M, Dezateux C, et al. Respiratory function among preterm infants whose mothers smoked during pregnancy. Am J Respir Crit Care Med 1998; 158:700-5.

13 Young S, Le Souef PN, Geelhoed GC, et al. The influence of a family history of asthma and parental smoking on airway responsiveness in early infancy. N Engl J Med 1991;324:1168-73

14 Bertrand JM, Riley SP, Popkin J, et al. The long term pulmonary sequelae of prematurity: the role of familial airway hyperreactivity and the respiratory distress syndrome. N Engl J Med 1985:312:742-5.

15 Duff AL, Pomeranz ES, Gelber LE, et al. Risk factors for acute wheezing in infants and children: viruses, passive smoke and $\lg E$ antibodies to inhalant allergens. Pediatrics 1993;92:535-40.

16 Pedreira FA, Guandolo VL, Feroli EJ, et al. Involuntary smoking and incidence of respiratory illness during the first year of life. Pediatrics 1985;75:594-7.

17 Tager IB, Hanrahan JP, Tosteson TD, et al. Lung function, pre and postnatal smoke exposure and wheezing in the first year of life. Am Rev Respir Dis 1993; 147:811-17.

18 Gilliland FD, Li Y-F, Dubeau L, et al. Effects of glutathione s-transferase M1, maternal smoking during pregnancy and environmental tobacco smoke on asthma and wheezing in children. Am J Respir Crit Care 2002;166:457-63.

19 Gergen PJ, Fowler JA, Maurer KR, et al. The burden of environmental tobacco smoke exposure on the respiratory health of children 2 months through 5 years in the United States: Third National Health and Nutrition Examination Survey, 1988-1994. Pediatrics 1998;101:e8.

20 Taylor B, Wadsworth J. Maternal smoking during pregnancy and lower respiratory tract illness in early life. Arch Dis Child 1987;62:786-91.

21 Rothman KJ. No adjustments are needed for multiple comparisons. Epidemiology 1990;1:43-6.

22 Perneger TV. What's wrong with Bonferroni adjustments. BMJ 1998;316:1236-8. 